\title{
Un análisis de los recursos didácticos empleados para el aprendizaje del tiempo histórico en los libros de texto de Educación Primaria
}

\section{An analysis of the didactic resources used to learn about historical time in Primary Education textbooks}

\author{
Alicia López Díaz y Josué Llull Peñalba
}

Centro Universitario Cardenal Cisneros

Resumen: La comprensión del tiempo es un requisito esencial para pensar históricamente. Sin embargo, la percepción infantil genera una serie de dificultades de aprendizaje que deben tratarse adecuadamente. En este artículo se hace una revisión de los aspectos teóricos relativos a la enseñanza del tiempo histórico. A continuación, se propone una herramienta de análisis de los contenidos relacionados con las nociones temporales y los recursos didácticos utilizados en los libros de texto de Educación Primaria. Finalmente, se presentan los resultados obtenidos tras la aplicación de dicha herramienta en una selección de libros de texto. Como conclusión, se demuestra la necesidad de complementar la utilización de los libros de texto con otros recursos didácticos

Palabras clave: Dificultades de Aprendizaje, Ciencias Sociales, Tiempo Histórico, Herramienta de Análisis, Libros de Texto.

Abstract: Comprehending time is a crucial requirement for thinking historically. However, children's perception provides several learning difficulties that must be adequately managed. This article presents a theoretical overview on the teaching of historical time. Afterwards, an analysis tool is proposed for the evaluation of the contents concerned with temporal notions and those didactic resources that are used in primary education textbooks. Finally, we show the results gathered after its application to a number of textbooks. As a conclusion, it is demonstrated that the use of complementary didactic resources apart from the one included in textbooks is necessary.

Keywords: Learning Difficulties, Social Sciences, Historical Time, Analysis Tool, Textbooks.

(Fecha de recepción: febrero, 2017, y de aceptación: julio, 2017)

DOI: 10.7203/DCES.32.9620 


\section{Introducción}

En el aprendizaje de cualquier disciplina existen una serie de nociones básicas que deben dominarse. La falta de comprensión de estas nociones ocasiona dificultades de aprendizaje, que afectan a una correcta adquisición de los contenidos escolares (Badia, 2013). En Ciencias Sociales los obstáculos se centran en el manejo de los conceptos de espacio y tiempo, ligados a las principales disciplinas que estructuran el área, la Geografía y la Historia (Comes y Trepat, 1998; Liceras, 2001; Hernández Cardona, 2002).

En estas páginas vamos a enumerar algunos recursos didácticos, que resultan útiles para facilitar un adecuado entendimiento de las nociones relacionadas con el tiempo histórico. En la línea de otros estudios, como los de Blanco Rebollo (2008) y Gómez Carrasco et al. (2014), nos interesa comprobar hasta qué punto los libros de texto de Educación Primaria incluyen recursos adecuados para el aprendizaje de la Historia. Porque a pesar de la creciente incorporación de otros muchos recursos, los libros siguen siendo un material indispensable en las aulas españolas. Para llevar a cabo la investigación, se ha diseñado una herramienta de análisis cuya finalidad es, primero, analizar el tratamiento que se hace del tiempo histórico en los libros de texto, y segundo, evaluar la existencia de determinados recursos didácticos. En el apartado de metodología se explicarán las características de esta herramienta y las categorías que analiza.
Para comprobar su validez, se ha aplicado al análisis de una muestra de diez libros de Educación Primaria. La selección de libros ha pretendido abarcar un abanico suficientemente diverso de editoriales, a manera de muestreo, con el fin de obtener resultados extrapolables. Por tanto, los objetivos de nuestra investigación son:

- Reflexionar sobre la importancia que tiene un adecuado manejo de las nociones temporales para superar las dificultades de aprendizaje en el área de Ciencias Sociales.

- Valorar la necesidad de utilizar recursos didácticos para el aprendizaje del tiempo histórico en los libros de Educación Primaria.

- Proponer la utilización de materiales complementarios al libro de texto para facilitar un aprendizaje más efectivo del tiempo histórico.

Al final se ofrecen los resultados obtenidos tras la implementación de esta herramienta. Nuestra conclusión principal es que existen numerosos recursos para el aprendizaje del tiempo histórico, pero que no siempre son convenientemente utilizados en los libros de texto. Ello no facilita la superación de las dificultades de aprendizaje habituales entre los niños.

\section{Marco teórico}

Dificultades de aprendizaje del tiempo histórico en el área de Ciencias Sociales 
Calvani (1993) situó el aprendizaje del tiempo como uno de los ejes centrales de la enseñanza de la Historia. Pero las competencias relacionadas con el manejo del tiempo se adquieren de forma gradual. Las investigaciones de la psicología evolutiva suelen dividir el proceso en varias etapas, de acuerdo con las ideas de Piaget, Ausubel y Vygotsky (Hernández Cardona, 2002). La mayoría de los autores coinciden en la necesidad de proveer experiencias significativas y cercanas al niño, con el fin de facilitar una mejor comprensión de la asignatura (Egan, 1991). El tiempo participa en muchos aspectos de la vida cotidiana, y eso puede servir de referencia para la enseñanza de contenidos en el área de Ciencias Sociales (Taylor y Young, 2003).

En el primer y segundo curso de la etapa de Educación Primaria, los procesos mentales del niño están ligados a las operaciones concretas. El niño concibe el medio de forma global, sin distinguir con claridad los elementos singulares que lo conforman, y establece relaciones por intuición, no por deducción. Por tanto, el desarrollo de las primeras nociones temporales está determinado por las propias vivencias, por un marcado egocentrismo y por la oposición de conceptos (Comes y Trepat, 1998). Así, el tiempo lejano o histórico, es entendido en ocasiones como algo ficticio.

En el tercer y cuarto curso de Primaria, el desarrollo cognitivo del niño sigue vinculado al estadio de las operaciones concretas y los aprendizajes están relacionados con sus vivencias.
Sin embargo, también se produce una progresiva transición hacia la siguiente etapa, en la que la visión egocéntrica del tiempo se difumina gracias a la interacción social, de tal forma que la mente del niño empieza a ser más objetiva (Alonso et al., 2010). A pesar de ello, la ficción sigue formando parte de su aprendizaje.

Finalmente, en quinto y sexto de Primaria, algunos alumnos entran en el estadio de las operaciones formales. Tienen mayor disposición para representar mentalmente ideas complejas, son más autónomos y sus expresiones verbales se enriquecen. Para un adecuado dominio del tiempo, se deben asentar las magnitudes, las nociones y el vocabulario temporal (Pozo, 1985). Ahora se entienden las principales etapas de la Historia e incluso es posible profundizar en el conocimiento de sucesos específicos. En cuanto a las propias vivencias, empiezan a relacionarse con otras fechas o eventos socialmente significativos. El uso de la cronología será fundamental para construir una adecuada concepción del tiempo (Pluckrose, 1993).

La psicología evolutiva es importante para adecuar los contenidos del área de Ciencias Sociales, pero también hay otros factores que influyen en el proceso de aprendizaje (Taylor y Young, 2003). Las etapas definidas por Piaget solo son orientativas; cada niño tiene un proceso de maduración distinto y necesitará de un tiempo diferente para adquirir los conceptos. Como profesores debemos tener en cuenta otros factores particulares de cada contexto educativo. 
Los estudios procedentes del ámbito anglosajón apuestan por un modelo de enseñanza en el que el alumno se convierte en protagonista de su aprendizaje. Metodológicamente, promueven la idea de dejar a los niños actuar como pequeños historiadores que investigan el pasado (Éthier et al., 2010). Esto favorece un proceso de aprendizaje más significativo sobre el tiempo y los conceptos históricos, que a la larga resulta más fácil de evaluar (Ercikan y Seixas, 2015). La necesidad de construir narraciones históricas coherentes, a partir de lo investigado, obliga a los alumnos a manejar adecuadamente el vocabulario y las unidades de medida del tiempo, facilitando una verdadera conciencia del pasado y de los conceptos temporales (Seixas y Morton, 2013).

La percepción del tiempo es otro aspecto de gran importancia. La primera gran diferencia que detectamos se relaciona con la distinción entre el tiempo personal que vive el niño, fruto de sus experiencias vitales, y el tiempo histórico, formado por acontecimientos pretéritos que el niño no percibe (Pagés y Santisteban, 2010). En los primeros años de vida se empieza a entender la medición del tiempo convencional gracias a las rutinas diarias. Ya en Primaria, se adquieren términos que permiten la estructuración temporal del día a día (el nombre de los días y los meses), y se entrena el uso del reloj. Hasta el estadio de operaciones formales no es posible representar de forma abstracta estas ideas mediante el pensamiento matemático (Pozo, 1985). En cuanto al tiempo histórico, su elemento más característico es el tiempo cronológico. Pero el tiempo histórico "se compone no sólo de fechas y de cronologías, sino también de las cosas que suceden en ese tiempo, es decir, de las relaciones causa-efecto, tanto inmediatas como remotas" (Ibídem, p. 15).

En resumen, la evolución del pensamiento temporal en el niño puede articularse mediante la distinción de tres tipos de tiempo: el tiempo vivido, el tiempo percibido y el tiempo concebido (Viñao, 1994). El tiempo vivido es fácil de entender para el niño, pues está relacionado con sus propias vivencias y experiencias. El tiempo percibido, a pesar de no experimentarse, puede comprenderse mediante el uso de unidades de medida, como el siglo, y su vinculación a la propia historia familiar; si el niño se acerca a las historias de sus antepasados puede deducir que, a pesar de no haberlo vivido, ese tiempo ha existido. Con el tiempo concebido, no obstante, es difícil establecer alguna conexión personal; se trata de un concepto muy abstracto y su aprendizaje se produce más tarde. Muchos autores aconsejan el uso de representaciones gráficas para abordar este tipo de temporalidad (Badia et al., 2013).

Para ver las diferencias establecidas entre cada tipo de tiempo, es necesario que los alumnos adquieran una serie de nociones temporales básicas, como son: cronología, causalidad, continuidad y vocabulario temporal.

a. Cronología. No se limita al estudio de las eras cronológicas. Los hechos históricos deben entenderse como 


\section{Cuadro I \\ Nociones temporales necesarias para dominar el tiempo histórico}

Fuente: Adaptado de Pozo (1985, p.14)

\begin{tabular}{|c|c|c|}
\hline \multirow{3}{*}{ Cronología } & Duración & $\begin{array}{l}\text { a) Horizonte temporal absoluto } \\
\text { b) Comparación entre períodos } \\
\text { c) Integración de unidades de medida }\end{array}$ \\
\hline & Orden & $\begin{array}{l}\text { d) Fechas anteriores y posteriores } \\
\text { e) Hechos y períodos anteriores y posteriores }\end{array}$ \\
\hline & Eras cronológicas & $\begin{array}{l}\text { f) Era después de Jesucristo } \\
\text { g) Era antes de Jesucristo } \\
\text { h) Convencionalidad del sistema: era musulmana }\end{array}$ \\
\hline \multirow[b]{2}{*}{ Sucesión causal } & Tiempo y causalidad & i) Consecuencias a corto y a largo plazo \\
\hline & Tipos de relación & $\begin{array}{l}\text { j) Causalidad lineal y simple } \\
\text { k) Causalidad múltiple y compleja }\end{array}$ \\
\hline $\begin{array}{l}\text { Continuidad } \\
\text { temporal }\end{array}$ & $\begin{array}{l}\text { Integración sincrónica } \\
\text { y diacrónica }\end{array}$ & $\begin{array}{l}\text { I) Ritmos de cambio social } \\
\text { m) Tiempos distintos simultáneos } \\
\text { n) Cambio y progreso }\end{array}$ \\
\hline
\end{tabular}

elementos conectados entre sí, no como una línea de tiempo singular, sino como "un entramado temporal dinámico, un tejido o malla temporal, más orgánico, donde se aprecie la concepción del tiempo como algo múltiple y diferenciado según su ritmo de cambio y duración" (Torres Bravo, 2001, p. 51). En el Cuadro I podemos distinguir que los conceptos clave en relación a la cronología son tres: la duración de los períodos históricos, la ordenación de las fechas y acontecimientos, y las magnitudes temporales. La Educación Primaria es el mejor momento para iniciarse en la enseñanza de estos conceptos. Antes de iniciar esta etapa, los niños ya poseen la habilidad de ordenar sucesos y contar narraciones en orden cro- nológico, y son capaces de establecer el inicio y el final de un cuento. En los primeros cursos, el uso de relatos y líneas de tiempo personales, el análisis de procesos sencillos y un uso adecuado de los tiempos verbales, serán muy útiles para aprender a secuenciar sucesos (Cooper, 2002).

b. Causalidad. Está muy determinado por el factor tiempo. Si el tiempo entre la causa y el acontecimiento es breve, hablamos de efectos a corto plazo; si la causa está más alejada en el tiempo, nos referimos al largo plazo. En cuanto a las relaciones establecidas, hay dos tipos de causalidad: lineal, es decir, que la causa solo desencadena una consecuencia; y múltiple, en la cual una causa puede desencadenar varias consecuencias de diferente 
índole (políticas, sociales, económicas, etc.). En las etapas de Infantil y Primaria los niños consideran que el efecto es siempre inmediato a la causa y tienen dificultades para adivinar las consecuencias de los acontecimientos históricos. Al finalizar la Primaria, empiezan a distinguir los componentes de la causalidad (causa y efecto), pero no de forma completa (Hernández Cardona, 2002). Por ello puede ser beneficioso aplicar a sus propias vivencias el manejo de relaciones causales. El ABP aplicado al análisis de los hechos históricos es una práctica interesante. Otra idea es que los ejes cronológicos que usemos en clase no tengan siempre una única trayectoria.

c. Continuidad. Es un concepto global basado en la distinción entre pasado, presente y futuro (Pagés y Santisteban, 2010). Sirve para determinar, por un lado, las características de las sociedades de cada época y los sucesos que se producen al mismo tiempo (sincrónicos), y por otro, los sucesos que se desarrollan en diferentes momentos (diacrónicos). Por tanto, las nociones que el alumno debe percibir tienen que ver con el cambio, la cronología y la causalidad, lo cual también puede aplicarse a su entorno más cercano (Badia et al., 2013). En Historia, son muchos los aspectos sociales que pueden analizarse de forma sincrónica o diacrónica. Un error muy frecuente se basa en la percepción del cambio como algo que siempre tiende al progreso, mientras que la permanencia supone un elemento de atraso. También hay problemas a la hora de distinguir entre el cambio social y el cambio vinculado al tiempo histórico. Mientras que el paso del tiempo no sufre interrupciones, el cambio social puede experimentar momentos de permanencia, retraso o evolución (Pozo, 1985). Por último, en relación con la cultura material, Cooper (2002) sostiene que los estudiantes son capaces de distinguir entre objetos de épocas pasadas y actuales.

d. Vocabulario temporal. Para la correcta comprensión del tiempo es necesario el uso de un vocabulario temporal amplio. A partir de los seis años, los niños suelen ser capaces de utilizar expresiones temporales sobre su día a día. Al final de la Primaria manejan marcadores temporales más específicos para referirse a situaciones alejadas de su propia experiencia (Taylor et al., 2003). La adquisición de estos conceptos no es sencilla, ya que el alumno tiene dificultades para ordenar los sucesos a partir de expresiones lingüísticas que no termina de comprender (Pellicer, 2006). Por ello es necesaria la realización de actividades en las que tengan que utilizar estas expresiones (Cuadro II).

Relacionado con este vocabulario está el uso de marcadores temporales, que Cooper (2002) clasifica atendiendo al estudio de diferentes contenidos (Cuadro III). 


\section{Cuadro II \\ Vocabulario temporal}

Fuente: Comes y Trepat, (1998, p. 55)

\begin{tabular}{|c|c|c|}
\hline Categorías & Subdivisión & Expresiones \\
\hline \multirow{3}{*}{ ORIENTACIÓN } & Presente & Ahora, hoy, en este momento \\
\hline & Pasado & Antes, ayer, hace tiempo, anterior, en otros tiempos, entonces \\
\hline & Futuro & $\begin{array}{l}\text { Después, mañana, más tarde, más adelante, en el futuro, } \\
\text { posteriormente }\end{array}$ \\
\hline \multirow[t]{2}{*}{ POSICIÓN } & Sucesión & $\begin{array}{l}\text { Antes, después, uno después de otro, uno por uno, más joven } \\
\text { que, más viejo que, más reciente que, más antiguo que, } \\
\text { primero, segundo }\end{array}$ \\
\hline & Simultaneidad & Al mismo tiempo que, durante, a la vez, juntamente \\
\hline \multirow{2}{*}{ DURACIONES } & Variabilidad & $\begin{array}{l}\text { Poco duradero, pasajero, efímero, menos tiempo que, tanto } \\
\text { tiempo como, más tiempo que, desde que/hasta que }\end{array}$ \\
\hline & Permanencia & $\begin{array}{l}\text { Duradero, estable, permanente, eterno, siempre, de entonces } \\
\text { hasta ahora }\end{array}$ \\
\hline
\end{tabular}

\section{Cuadro III \\ Marcadores temporales de la Historia}

Fuente: Cooper (2002, p. 29)

\begin{tabular}{|l|l|}
\hline Categorías & Expresiones \\
\hline Registro del pasado del tiempo & Año, década, generación, siglo \\
\hline Cambios que se producen en el tiempo & Antiguo, nuevo, igual, diferente, causa, efecto \\
\hline Características comunes de determinados períodos & Romano, victoriano \\
\hline $\begin{array}{l}\text { Ideas organizadores que están presentes en } \\
\text { todas las sociedades y que no son exclusivamente } \\
\text { históricos }\end{array}$ & $\begin{array}{l}\text { Agricultura, comercio, comunicación, } \\
\text { creencias }\end{array}$ \\
\hline $\begin{array}{l}\text { Edificios, tecnología o grupos de personas que } \\
\text { corresponden a épocas pasadas }\end{array}$ & Castillo, caballero, villa romana, galeón \\
\hline
\end{tabular}

Algunos recursos que facilitan el aprendizaje del tiempo histórico

Los recursos didácticos "contribuyen a elevar la motivación y mejorar el ambiente y las situaciones de aprendi- zaje [...] todo ello con el fin de hacer más comprensible el mundo que nos rodea y las disciplinas sociales que los estudian" (García Ruíz, 1993, p. 101). En el área de Ciencias Sociales existen muchos recursos que pueden ser utilizados para 
favorecer el desarrollo del pensamiento histórico-temporal. Hemos seleccionado los siguientes: líneas de tiempo, mapas conceptuales, fuentes escritas, fuentes orales, imágenes, objetos materiales y recursos multimedia.

\section{Líneas de tiempo}

Se trata de una "línea horizontal o vertical, que representa el transcurso del tiempo a lo largo de su extensión" (Alonso et al., 2010, p. 82). En los primeros cursos de Educación Primaria, las líneas de tiempo pueden estar relacionadas con las experiencias directas del niño o con su propia historia, para que aprendan a destacar acontecimientos de su vida. A partir del tercer y cuarto curso, esta línea de tiempo personal puede incorporar datos de sus familiares más cercanos; así, el niño aprenderá unidades de tiempo más amplias, como una década o un siglo, y comprenderá aspectos de la evolución social. En los últimos cursos, es posible trabajar con líneas de tiempo vinculadas a períodos más amplios o a determinados temas históricos, así como líneas comparativas e interrelacionadas, que conecten aspectos locales, nacionales e internacionales. Se recomienda, además, el uso de escalas variadas para medir los datos históricos, que los intervalos temporales sean equivalentes, y que se complementen con actividades en las que utilizar vocabulario y marcadores temporales. Taylor et al. (2003) clasifican las líneas de tiempo en varios tipos: personales, unidimensionales, multi- dimensionales, transversales, visuales, etc. Por su parte, Pluckrose (1993) propone el uso de diagramas cronológicos como alternativa a las líneas de tiempos. Estos diagramas son dibujos sencillos acompañados de breves datos cronológicos y resultan muy efectivos, por ejemplo, para el análisis de monumentos históricos.

\section{Mapas conceptuales}

Los mapas conceptuales sirven para presentar información de manera esquemática, resumir un texto amplio o establecer conexiones entre diversos contenidos. Fernández (1992) considera que la construcción de un mapa conceptual permite poner en práctica el vocabulario específico de la asignatura, y López Facal (1992) relaciona este tipo de técnicas con un modelo de aprendizaje constructivista y significativo. En relación con el tiempo histórico, los mapas permiten presentar de forma conjunta e interrelacionada los diferentes conceptos de una unidad didáctica, de resultas que el alumno no los percibe de forma aislada. Además, facilitan el desarrollo del pensamiento cronológico, porque en un mapa conceptual las fechas son datos importantes, con relevancia visual, y los nexos utilizados son en ocasiones marcadores temporales. Finalmente, se afianza la noción de causa-efecto porque la información se distribuye de forma secuenciada y/o jerárquica, y sus relaciones pueden ser históricas. Es decir, un hecho histórico (efecto) está precedido por una serie de 
factores (causas) y así debe expresarse en el mapa conceptual. Para afianzar la noción de causalidad, Llonch (2011, p. 98) recomienda el mapa de tipo "arboriforme, donde el organigrama parte de un concepto que se quiere priorizar y de éste salen ramas más o menos paralelas, con capacidad de conectarse".

\section{Fuentes escritas}

El estudio de los hechos históricos se fundamenta en el análisis y la comparación de diversas fuentes de información, esencialmente textuales. Cuanto más variadas sean las fuentes a las que tengan acceso los estudiantes, más objetivo y crítico será su pensamiento histórico (Hernández Cardona, 2002). Según Pluckrose (1993, p. 157), "el acceso a una serie de materiales impresos permite forzosamente la exposición de diferentes puntos de vista. Su misma presencia [...] estimulará a los alumnos a formular preguntas". Por consiguiente, el análisis comprensivo y crítico de los textos favorece un aprendizaje significativo de la Historia.

La actividad más recurrente con las fuentes escritas es el comentario de texto. En el aula de Primaria, deben despertar el interés de los niños, ser claros y evitar una extensión excesiva. Los libros de texto suelen incluir extractos de fuentes históricas, que pueden complementarse con otros libros especializados, como enciclopedias y biografías (García Ruíz, 1993). La prensa también es una buena herramienta; el análisis de noticias a partir de fichas técnicas, la creación de artículos propios y la producción de bancos de noticias son algunas propuestas prácticas (Alonso et al., 2010). Los textos con historicidad, como las cartas, las declaraciones, etc. pueden facilitar el acercamiento a otras épocas históricas porque revelan su antigüedad de forma directa. Cuando el niño accede a documentos "antiguos" o facsímiles es capaz de ver las diferencias con respecto a la actualidad e imaginar un tiempo pasado, distinto del presente. Además, tiene la oportunidad de sentirse como un auténtico historiador. Luc (1981) propone la visita a archivos y bibliotecas para que los niños tengan acceso a fuentes históricas. Se trata de experiencias muy motivadoras en las que investigan de manera real y desarrollan una serie de competencias tanto científicas como sociales.

\section{Fuentes orales}

Nos referimos a un vasto conjunto de fuentes de información no escrita, que pueden tener valor histórico, por ejemplo, los testimonios de vida y los recuerdos personales. Son relevantes porque nos ayudan a entender los acontecimientos más recientes de la Historia y permiten el desarrollo de la conciencia temporal (Hernández Cardona, 2002). Los niños pueden entrar en contacto con experiencias reales, anteriores a las suyas, preguntando a sus padres y abuelos. Invitar a la clase a personas con un pasado histórico relevante es otra propuesta interesante (Luc, 1981). Es aconsejable la preparación previa de pregun- 
tas, a modo de entrevista, y la organización de fichas en las que registrar de forma sistemática la información.

Según Pluckrose (1993), se pueden desarrollar varios tipos de actividades educativas con fuentes orales: estudios familiares, estudios comunitarios y estudios biográficos. Los primeros constituyen una forma de aproximarse a la historia más cercana del alumno, tomando como punto de partida su propio presente para luego reconstruir la evolución experimentada por los miembros más viejos de su familia. La utilización de genealogías y narraciones puede ayudar como recurso complementario. Una vez que el estudiante se ha identificado como persona de la sociedad, podemos iniciarle en un estudio más amplio sobre una comunidad humana. Los estudios comunitarios son útiles para que los niños comprendan el origen y evolución del entorno más cercano, como la ciudad o el barrio, y así puedan contextualizar la historia de su familia, y la suya misma, como parte de la sociedad, por ejemplo, a través del análisis de los edificios, de su evolución y de las funciones que han desempeñado a lo largo del tiempo. Por último, Alonso et al. (2002) identifican los estudios biográficos con la investigación sobre la vida de un personaje. La datación de fechas relevantes en su trayectoria, así como la sucesión causal de los hechos producidos por sus acciones, favorecen el aprendizaje de contenidos temporales como la cronología. Si el personaje elegido resulta próximo al alumno, por haber nacido en la misma ciudad o por otra razón, la experiencia es aún más significativa.

\section{Imágenes}

En Historia, el acompañamiento de imágenes resulta fundamental para hacer visible las explicaciones del profesor, para extraer de ellas información relevante sobre una época determinada y para promover su carácter interdisciplinar, por ejemplo, en sus relaciones con el arte. La iconografía ayuda a interpretar las obras de arte a partir del análisis de su contexto histórico "para saber lo que nos cuentan sobre usos y costumbres de nuestros antepasados o de otras civilizaciones; para saber cuál ha sido la evolución tecnológica que ha tenido [y] para saber algo sobre la evolución conceptual, usos, gustos y aversiones" (Castillo, 2010, p. 69). En cuanto al tipo de imágenes históricas que podemos utilizar, además de las obras de arte, contamos con la fotografía histórica y los carteles propagandísticos. También las representaciones de sucesos y ambientes históricos, como las que proporcionan el teatro, el cómic, las recreaciones digitales de espacios arqueológicos, los documentales y, sobre todo, el cine, que deben analizarse de manera crítica (Cabrera, 2013). Son de gran utilidad para visualizar las costumbres y modos de vida de las sociedades antiguas, establecer comparaciones, interpretar mensajes y símbolos, etc. Por último, merecen especial atención los retratos de personajes históricos, que además de ponerle 
rostro al pasado, invitan a reflexionar sobre el papel de los sujetos históricos y a desarrollar la empatía mediante la conexión emocional.

\section{Objetos materiales}

Los alumnos acceden a estas fuentes a través de las visitas a los museos y yacimientos arqueológicos, donde pueden observar de cerca los testimonios de las sociedades antiguas y advertir el paso del tiempo en su materialidad física (García Ruíz, 1993). Una reflexión sobre su estado de conservación y los factores que influyen en su deterioro es aconsejable. Otra opción es que los profesores lleven al aula objetos reales o réplicas, y permitir a los niños tocarlos y manipularlos. Estos realia workshops son frecuentes en el ámbito anglosajón, y pretenden hacer significativo el aprendizaje mediante la interacción entre los alumnos y los objetos materiales (Herrel y Jordan, 2007).

Los recursos materiales pueden clasificarse en dos grandes tipos: arqueológicos y etnográficos. Los primeros aportan información sobre la prehistoria y las sociedades antiguas; su valor estriba en el hecho de constituir expresiones culturales de sociedades ya desaparecidas, lo que las hace excepcionales. Los objetos etnográficos suelen estar vinculados al "folclore, las costumbres, las tradiciones, los juegos, las fiestas, etc. [y] constituyen toda una cultura que no podemos ignorar [porque] son los lazos que nos unen con el pasado y que tenemos que tener como referencia para el futuro, si queremos que este sea próspero, pero humanizado y con identidad" (García Ruíz, 1993, p. 112). Las familias conservan en sus casas muchos objetos personales que pertenecen a un pasado reciente, con frecuencia ligado al medio rural, o bien adquiridos mediante el turismo en otros países. Su interés reside en su capacidad para establecer comparaciones entre sociedades y épocas distintas (Hernández Cardona, 2002).

\section{Recursos multimedia}

Además de los recursos audiovisuales, en esta categoría destacan por encima de todo Internet y las TICs. En los últimos años, la aparición de páginas web interactivas, animaciones multimedia y otros recursos han supuesto una verdadera revolución educativa que muchos profesores aún están tratando de integrar en sus clases (Prats y Albert, 2004). Entre las herramientas más versátiles están las pizarras y las tabletas digitales, que permiten una aproximación multidisciplinar, simultánea y diversificada de los contenidos. La incorporación de estos recursos a la didáctica constituye uno de los avances más relevantes de la actualidad, pero su simple presencia no garantiza un mejor aprendizaje. El maestro debe desarrollar actitudes como la reflexión sobre su uso y los objetivos que se persiguen con cada aplicación (Buzo, 2011). En relación con el aprendizaje del tiempo, los recursos multimedia permiten a los niños la creación de sus propias 
líneas de tiempo, comics, mapas conceptuales, etc., que son válidos para desarrollar las nociones temporales. En todo caso, recomendamos la investigación de Flores y Rivero (2014), centrada en los errores que suelen cometer los profesores a la hora de seleccionar herramientas digitales para fomentar el pensamiento histórico.

\section{Metodología}

Diseño de la herramienta de análisis

Los objetivos específicos relacionados con la puesta en práctica de nuestra investigación han sido los siguientes:

- Diseñar una herramienta de análisis para evaluar los aspectos didácticos relacionados con el aprendizaje del tiempo histórico en una selección de libros de texto de Educación Primaria.

- Analizar la inclusión de explicaciones y/o actividades sobre las nociones temporales en los libros seleccionados.

- Analizar la inclusión de recursos didácticos para la comprensión del tiempo histórico en los libros de texto seleccionados.

Hemos diseñado una herramienta a modo de lista de control, compuesta por treinta ítems. Cada ítem tiene un valor de un punto y se otorga en función de si existe o no. La calificación máxima que puede alcanzar cada libro de texto es de treinta puntos. Hay un apartado inicial de "Información sobre el libro de texto", que no es cuantificable porque solo recoge datos como el título del libro, año de edición, editorial, curso escolar al que va dirigido y legislación vigente en el momento de su publicación.

La primera parte de la herramienta se titula "Enseñanza de las nociones temporales", e incluye ocho ítems para evaluar las explicaciones y las actividades didácticas que aparecen en los libros sobre las cuatro nociones temporales comentadas en el marco teórico.

- Cronología. Se comprueba si se explican contenidos tales como la duración, el orden, las eras cronológicas, los períodos históricos, etc., de acuerdo con las orientaciones de Torres Bravo (2001) y Cooper (2002).

- Sucesión causal. Se observa si hay relaciones de causalidad a corto y/o largo plazo; se tiene en cuenta si hay causalidades lineales y simples, o múltiples y complejas, según apunta Hernández Cardona (2002).

- Continuidad temporal. Se analiza si hay conceptos vinculados al cambio social y al progreso, según las indicaciones de Pozo (1985), Cooper (2002), Pagés et al. (2010), y Badia et al. (2013).

- Marcadores temporales. Se valora la presencia de un vocabulario histórico específico que ayude al alumno a expresarse temporalmente, según explican Comes y 
Trepat (1998), Taylor et al. (2003) y Pellicer (2006).

La segunda parte de la herramienta se refiere a los "Recursos didácticos sobre el tiempo histórico" y se compone de veintidós ítems categorizados en los seis tipos de recursos que facilitan el aprendizaje del tiempo histórico. Hemos valorado la presencia de cada recurso, desde un punto de vista teórico, y su utilización a través de las actividades propuestas.

- Líneas de tiempo. Se evalúa si hay ejemplos diversos de líneas de tiempo (Taylor et al., 2003), variantes como los diagramas cronológicos propuestos por Pluckrose (1993), y si hay actividades de análisis e interpretación de líneas de tiempo o de producción de líneas propias (Alonso et al., 2010).

- Mapas conceptuales. Se comprueba si hay ejemplos ya elaborados y también actividades de producción de mapas conceptuales, según las indicaciones sugeridas por Fernández (1992), López Facal (1992) y Llonch (2011).

- Fuentes escritas. Se evidencia si hay textos que sirvan para acercar al alumno a las fuentes históricas, según plantean Luc (1981), Pluckrose (1993), García Ruíz (1993), Hernández Cardona (2002) y Alonso et al. (2010). También si existen fichas para analizar fuentes escritas, actividades de comentario de textos y actividades de producción de textos históricos a partir de un modelo predeterminado.

- Fuentes orales. Se valora si hay modelos o fichas para registrar, por ejemplo, entrevistas (Luc, 1981), si se proponen estudios comunitarios (Pluckrose, 1993), y si hay prácticas de investigación relacionadas con las fuentes orales, como las sugeridas por Hernández Cardona (2002) y Alonso et al. (2010).

- Imágenes y objetos. Se observa si hay imágenes histórico-artísticas, fotográficas, etc. (Castillo, 2010), imágenes de objetos arqueológicos o etnográficos, como los señalados por García Ruíz (1993) y Hernández Cardona (2002), u otro tipo de imágenes como cómics o dibujos que recrean sucesos y/o personajes históricos.

- Recursos multimedia. Se evalúa si el libro de texto está adaptado a los cambios tecnológicos mediante la inclusión de enlaces de internet, actividades digitales y audiovisuales, como las definidas por Buzo (2011) y Flores y Rivero (2014). También si hay modelos para analizar recursos multimedia, así como actividades de repaso o de ampliación a través de las TICs.

\section{Aplicación de la herramienta}

La herramienta se ha aplicado al análisis de una muestra de libros de texto, 


\section{Cuadro IV. Herramienta de análisis de los recursos didácticos empleados para el aprendizaje del tiempo histórico en los libros de texto de Educación Primaria}

Fuente: Elaboración propia

\begin{tabular}{llll}
\multicolumn{4}{l}{ INFORMACIÓN SOBRE EL LIBRO DE TEXTO } \\
$\square$ & Título: & $\square$ & Curso escolar: \\
$\square$ & Año y Editorial: & $\square$ & Legislación vigente:
\end{tabular}

ENSEÑANZA DE LAS NOCIONES TEMPORALES

1. Cronología

- Enseñanza de la cronología (duración, orden, eras cronológicas, períodos históricos, etc.)

- Actividades didácticas sobre la cronología

2. Sucesión causal

- Enseñanza de la sucesión causal (tiempo y causalidad y tipos de relación)

- Actividades didácticas sobre la sucesión causal

3. Continuidad temporal

- Enseñanza de la continuidad temporal (cambio social, progreso, etc.)

- Actividades didácticas sobre la continuidad temporal

4. Marcadores temporales

- Enseñanza de los marcadores temporales

- Actividades didácticas sobre los marcadores temporales

RECURSOS DIDÁCTICOS SOBRE EL TIEMPO HISTÓRICO

1. Líneas de tiempo

- Presencia de líneas de tiempo

- Presencia de otras variantes como diagramas cronológicos

- Actividades de análisis e interpretación de líneas de tiempo

- Actividades de producción de líneas de tiempo históricas

- Actividades de producción de líneas de tiempo personales

2. Mapas conceptuales

- Presencia de mapas conceptuales

- Actividades de producción de mapas conceptuales 
- Presencia de textos históricos

- Presencia de modelos o fichas para analizar fuentes escritas

- Actividades de comentario de textos e interpretación de fuentes escritas

- Actividades de producción de textos históricos a partir de un modelo (ej.: noticia periodística)

4. Fuentes orales: testimonios, estudios familiares y comunitarios, estudios biográficos

- Presencia de modelos o fichas para registrar fuentes orales (ej.: entrevistas)

- Presencia de modelos o fichas para hacer estudios familiares o comunitarios (ej.: esquemas cronológicos)

- Actividades de producción e investigación relacionadas con las fuentes orales (ej.: biografías)

5. Imágenes y objetos

- Presencia de imágenes históricas (pintura, fotografía histórica, etc.)

- Presencia de imágenes de objetos (etnográficos, arqueológicos, de la vida cotidiana, etc.)

- Presencia de ilustraciones, cómics, dibujos, etc., que recrean sucesos y/o personajes históricos

- Presencia de modelos o fichas para analizar imágenes

- Actividades de análisis e interpretación de imágenes

6. Recursos audiovisuales y multimedia

- Presencia de modelos o fichas para analizar recursos audiovisuales (cine, documentales)

- Actividades de investigación y búsqueda de información a través de las nuevas tecnologías

- Actividades de repaso de la unidad a través del uso de recursos multimedia

seleccionados en función de diversos criterios. Primero, que hubieran sido editados bajo las últimas leyes educativas (LOGSE, LOE y LOMCE), con el fin de advertir los cambios experimentados en el currículum. Segundo, que pertenecieran a editoriales distintas, ya que cada una desarrolla un proyecto diferenciado a la hora de presentar los contenidos y actividades. Tercero, que estuvieran dirigidos a los niveles intermedios de la Educación Primaria, para que los contenidos vinculados al tiempo histórico tuvieran un tratamiento similar. Como criterio adicional, se han elegido algunos libros destinados a programas de enseñanza bilingüe, con el fin de analizar posibles adaptaciones metodológicas. En el Cuadro V se señalan, con un número y un color diferentes, los libros de texto analizados. 


\section{Cuadro V. Libros de texto analizados}

Fuente: Elaboración propia

\begin{tabular}{|c|c|c|c|}
\hline Título & Editorial y año & Curso & Designación \\
\hline Social Science 3. Comunidad de Madrid & ByME, 2014 & $3^{\circ}$ & Libro 1: rojo \\
\hline $\begin{array}{l}\text { New World 5. Natural, Social and Cultural } \\
\text { Environment }\end{array}$ & Vicens Vives, 2011 & $5^{\mathrm{o}}$ & Libro 2: amarillo \\
\hline Macmillan Natural and Social Science Level 4 & Macmillan, 2011 & $4^{\circ}$ & Libro 3: verde \\
\hline $\begin{array}{l}\text { Conocimiento del Medio 4. Madrid. } 3^{\text {er }} \text { Trimestre. } \\
\text { Proyecto Abre la Puerta }\end{array}$ & Anaya, 2010 & $4^{\mathrm{o}}$ & Libro 4: naranja \\
\hline $\begin{array}{l}\text { Conocimiento del medio 5. Proyecto La Casa del } \\
\text { Saber }\end{array}$ & Santillana, 2009 & $5^{\mathrm{o}}$ & Libro 5: rosa \\
\hline Science and Environment 4. My World Project & Edelvives, 2008 & $4^{\circ}$ & Libro 6: azul \\
\hline Science 4. Proyecto Tirolina & $\mathrm{SM}, 2008$ & $4^{\circ}$ & Libro 7: marrón \\
\hline Conocimiento del medio 4. Proyecto Alavista & Edelvives, 2006 & $4^{\mathrm{o}}$ & Libro 8: gris \\
\hline Conocimiento del Medio 4. Enclave & Bruño, 1993 & $4^{\circ}$ & Libro 9: morado \\
\hline $\begin{array}{l}\text { Conocimiento del Medio de } 4^{\circ} \text { curso de Ed. } \\
\text { Primaria. Proyecto. } \mathrm{H}^{\mathrm{a}} \text { de las Cosas }\end{array}$ & Santillana, 1993 & $4^{\mathrm{o}}$ & Libro 10: negro \\
\hline
\end{tabular}

\section{Resultados. Discusión}

Las puntuaciones obtenidas en cada criterio por cada uno de los libros han sido sintetizadas mediante gráficos de barras. El del Cuadro VI recoge las puntuaciones globales. Las más altas corresponden a los libros 1 y 5 aunque no son muy significativas porque apenas superan la media (15 puntos). Por el contrario, los libros 7 y 9 han obtenido los resultados más bajos.

En la enseñanza de las nociones temporales, sobresalen los libros 5,9 y 10 , que tratan sobre todo aspectos relacionados con la cronología y los marcadores temporales. Para mayor claridad, se ha elaborado un gráfico de sectores que muestra la representación media que ha alcanzado cada una de las nociones temporales (Cuadro VII). Se puede constatar que la cronología es la noción temporal más explicada y la sucesión causal la que menos.

En cuanto a los recursos didácticos, estos tienen mayor presencia en los libros 1,2 y 5 , y más escasa en los libros 7 y 9 . Los mapas conceptuales y las imágenes son los más habituales, seguidos de las líneas de tiempo. El uso de otros recursos desciende hasta llegar a las fuentes escritas y los recursos multimedia, que son minoritarios. En el Cuadro VIII se puede apreciar la representación media que tiene cada uno de los recursos didácticos en los libros analizados. 


\section{Cuadro VI. Puntuaciones globales de los libros analizados}

Fuente: Elaboración propia

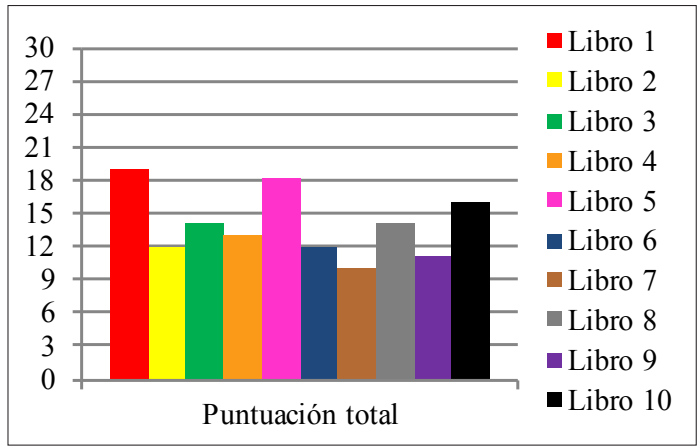

\section{Cuadro VII. Representación media} de la enseñanza de las nociones temporales

Fuente: Elaboración propia

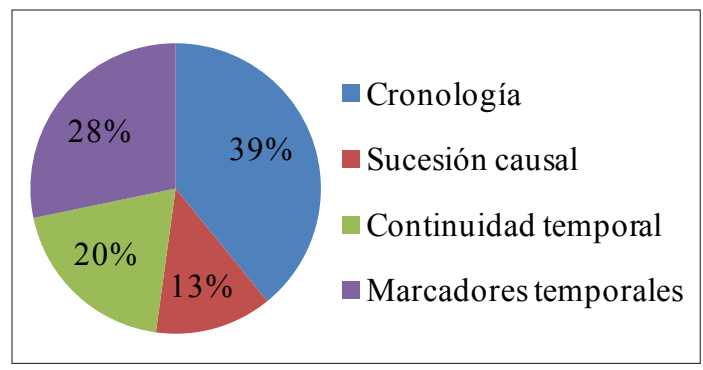

Cuadro VIII. Representación media de los recursos didácticos sobre el tiempo histórico

Fuente: Elaboración propia

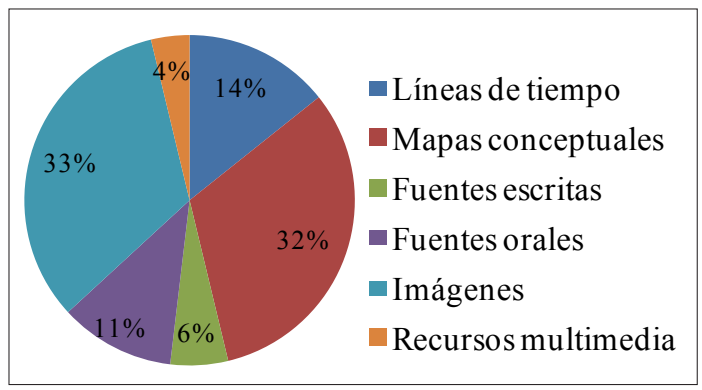

$\mathrm{Al}$ igual que en la investigación de Blanco Rebollo (2008), nuestro análisis se ha centrado en los contenidos y en los recursos. Pensamos que los datos son extrapolables, puesto que la muestra es significativa y diversa. Los resultados sugieren que los libros de texto presentan carencias en relación a la enseñanza del tiempo. Por ello, su uso debería ser complementado por otros materiales didácticos. A pesar de ser la base sobre la que se construye el pensamiento histórico, las nociones temporales no están suficientemente explicadas, exceptuando la cronología. El uso de marcadores y vocabulario histórico especializado se ha ido incorporando en los libros más recientes, pero la sucesión causal y la continuidad temporal quedan relegadas a un plano residual.

En cuanto a los recursos didácticos, uno de los mayores déficits se refiere a las fuentes escritas, quizás porque se consideran difíciles en Primaria. Por su parte, las fuentes orales son poco utilizadas, lo cual soslaya experiencias significativas para el alumno. Los recursos multimedia han alcanzado cierto protagonismo en los libros más recientes, lo que demuestra su adaptación a los nuevos tiempos. En el lado opuesto destacamos algunas actividades didácticas, que son demasiado simples y se limitan a resumir la información aportada en el cuerpo del texto. Falta introducir tareas que impliquen el desarrollo de proyectos más exigentes. Pero nuestro propósito no es criticar las carencias que presentan los libros escolares. Se trata de reflexionar sobre el modo en 
que se transmiten los aspectos relacionados con la temporalidad. Según Saab (1997) y González (2006), el profesor debe conocer los libros y los contenidos que tratan, para planificar la manera de consolidarlos y, si es necesario, complementarlos con otros recursos.

\section{Conclusiones}

Este estudio sobre la transmisión de los contenidos temporales en el área de Ciencias Sociales constata las dificultades más habituales entre los niños de Educación Primaria. Son muchos los factores que influyen en los procesos de enseñanza-aprendizaje y, tanto los maestros en ejercicio como los pedagogos, tienen la responsabilidad de conocer cuáles son los recursos didácticos más adecuados. Todo ello con el objetivo de adaptar la metodología y favorecer un aprendizaje más eficaz, a pesar de la complejidad que pueda presentar una determinada asignatura.

Las propuestas didácticas derivadas del uso de los libros de texto analizados no facilitan un aprendizaje completo del tiempo histórico. El maestro debe hacer un uso complementario de otros recursos y actividades. Para ello es esencial un trabajo continuo de investigación sobre metodologías innovadoras en la enseñanza de la Historia, con el fin de promover aprendizajes significativos y experimentales, que permitan al alumno comprender mejor los conceptos temporales. Desde nuestro punto de vista, sería de gran interés comparar lo que se hace en las aulas españolas con otros modelos internacionales, en especial con el tipo de actividades centradas en el alumno, características del mundo anglosajón. En países como Inglaterra o Estados Unidos se pone al estudiante en el rol de un pequeño historiador, capaz de construir su propio aprendizaje a partir de la investigación autónoma, el ABP y el trabajo por proyectos.

Los resultados obtenidos en nuestra investigación nos llevan a proponer nuevos objetivos para el futuro. El modelo de investigación desarrollado puede ser trasladado a otras disciplinas del área de Ciencias Sociales. Aquí nos hemos centrado en las dificultades de aprendizaje propias de la Historia, y hemos indagado sobre los recursos didácticos más adecuados para afrontarlas. En otra ocasión sería interesante tratar los problemas que pueda presentar, por ejemplo, la enseñanza de la Geografía, proponiendo sugerencias válidas para resolverlos. Al igual que las nociones temporales son el elemento vertebrador de la Historia, las nociones espaciales constituyen el eje sobre el que se construye el pensamiento geográfico.

Las dificultades de aprendizaje detectadas en la Educación Primaria no solo conciernen al área de Ciencias Sociales. También tienen implicaciones en otras asignaturas como Matemáticas o Lengua Castellana. Pero si definimos bien las nociones y los recursos didácticos para tratar los contenidos más complejos de cada asignatura, construiremos los cimientos sobre los que poder desarrollar una enseñanza más eficiente. Estos problemas deben 
resolverse adecuadamente en la etapa de Primaria, porque los alumnos tendrán que enfrentarse a otras barreras similares en la Educación Secundaria, donde los conocimientos y las competencias a adquirir son evidentemente más complejos y abstractos.

\section{Referencias bibliográficas}

ALONSO, S.; GONZÁLEZ, S.; GONZÁLEZ, A.P.; GONZÁLEZ, M. (2010). Didáctica de las Ciencias Sociales para la Educación Primaria. Madrid: Pirámide.

BADIA, A. et al. (2013). Las dificultades en el aprendizaje escolar de los contenidos curriculares. Barcelona: UOC.

BLANCO REBOLLO, A. (2007). La representación del tiempo histórico en los libros de texto de primero y segundo de la enseñanza secundaria obligatoria. Tesis Doctoral, Universitat de Barcelona.

BUZO SÁNCHEZ, I. (2011). La cotidianidad en el uso de las TIC en Ciencias Sociales. La web de recursos de Ciencias Sociales. En HERNÁNDEZ, J.; PENNESI, M.; SOBRINO, D.; VÁZQUEZ, A. (coords.), Experiencias educativas en las aulas del siglo XXI: Innovación con TIC (347-350). Madrid: Ariel.

CABRERA ASENSIO, J. (2013). Las recreaciones históricas y sus fund amentos. ASRI: Arte y Sociedad. $\mathrm{n}^{\circ}$ 3. Recuperado de http://asri.eumed. net/3/recreaciones-historicas-fundamentos.pdf [30 de junio de 2017].
CALVANI, A. (1993). Il bambino, il tempo, la storia. Florencia: La Nuova Italia.

CASTILLO, C.A. (2010). El estudio de las imágenes. Revista de educación y pensamiento, $\mathrm{n}^{\circ} 17,67-75$.

COMES, P. y TREPAT, C.A. (1998). $E l$ tiempo y el espacio en la didáctica de las ciencias sociales. Barcelona: Graó - ICE de la Universidad de Barcelona.

COOPER, H. (2002). Didáctica de la Historia en la Educación Infantil y Primaria. Madrid: Morata.

EGAN, K. (1991). La comprensión de la realidad en la Educación Infantil y Primaria. Madrid: Ed. Morata.

ERCIKAN, K. y SEIXAS, P. (2015). New directions in assessing historical thinking. New York: Routledge.

ÉTHIER, M-A.; DEMERS, S.; LEFRANÇOIS, D. (2010). Las investigaciones en didáctica sobre el desarrollo del pensamiento histórico en la enseñanza primaria. Una panorámica de la literatura publicada en francés e inglés desde el año 1990. Enseñanza de las ciencias sociales 9, 61-74.

FERNÁNDEZ, T. (1992). Mapas conceptuales y diagramas UVE. Dos estrategias en la enseñanza de la historia. Comunicación, lenguaje y educación, $\mathrm{n}^{\circ} 16,7-24$. DOI: $10.1080 / 02147033.1$ 992.10821047.

FLORES HOLE, H.C. y RIVERO GRACIA, P. (2014). ¿Cómo selecciona el profesorado recursos digitales para enseñar la Historia? Clío. History and History Teaching, $\mathrm{n}^{\circ}$ 40, 7-10. 
GARCÍA RUÍZ, A.L. (1993). Didáctica de las ciencias sociales en la educación primaria. Madrid: Algaida.

GÓMEZ CARRASCO, C.J.; CÓZAR GUTIÉRREZ, R.; MIRALLES MARTÍNEZ, P. (2014). La enseñanza de la historia y el análisis de libros de texto. Construcción de identidades y desarrollo de competencias. Ensayos: Revista de la Facultad de Educación de Albacete, Vol. 29, 1, 1-25.

GONZÁLEZ, M.P. (2006). Conciencia histórica y enseñanza de la historia: una mirada desde los libros de texto. Enseñanza de las ciencias sociales, $\mathrm{n}^{\circ}$ 5, 21-30.

HERNÁNDEZ CARDONA, F.X. (2002). Didáctica de las Ciencias Sociales, geografía e historia. Barcelona: Graó. HERREL, A.L. y JORDAN, M.L. (2007). Fifty Strategies for Teaching English Language Learners. Boston, M. A.: Pearson.

LICERAS, A. (2001). La Atención a las Dificultades en el Aprendizaje de las Ciencias Sociales. En TONDA, E. M. y MULA, A. (coord.), Scripta in Memoriam. Homenaje al profesor Jesús de Vera Ferre (217-225). Alicante: Servicio de Publicaciones de la Universidad.

LLONCH MOLINA, N. (2011). Enseñar historia: indumentaria y mapas conceptuales. Íber: Didáctica de las ciencias sociales, geografía e historia, $\mathrm{n}^{\circ}$ $69,95-101$.

LÓPEZ FACAL, R. (1992). Mapas conceptuales y enseñanza de las ciencias sociales. Aula de innovación educati$v a, \mathrm{n}^{\circ} 8(1), 31-35$.

LUC, J.N. (1981). La enseñanza de la Historia a través del medio. Madrid: Cincel.

PAGÉS, J. y SANTISTEBAN, A. (2010). La enseñanza y el aprendizaje del tiempo histórico en la educación primaria. Cedes, ${ }^{\circ}$ 82(30), 281-301. DOI: 10.1590/s0101-32622010000300002.

PELLICER, A. (2006). Reconstrucción de la temporalidad a partir de la lectura de textos didácticos con contenido histórico. Estudio psicolingüístico con alumnos de educación básica. Lectura y vida: Revista latinoamericana de lectura, $\mathrm{n}^{\circ} 3(27), 16-27$.

PLUCKROSE, H. (1993). Enseñanza y aprendizaje de la Historia. Madrid: Morata.

POZO, I. (1985). El niño y la historia. Madrid: Servicio de Publicaciones del Ministerio de Educación y Ciencia.

PRATS, J. y ALBERT, J. (2004). Enseñar utilizando internet como recurso. Íber: Didáctica de las ciencias sociales, geografía e historia, $\mathrm{n}^{\circ}$ 41, 8-18.

SAAB, J. (1997). La enseñanza de la Historia y los libros de texto. Clio \& asociados: la historia enseñada, $\mathrm{n}^{\circ} 2,115$ 122. DOI: $10.14409 /$ cya.v1i2.1512.

SEIXAS, P. y MORTON, T. (2013). The Big Six Historical Thinking Concepts. Toronto: Nelson.

TAYLOR,T.y YOUNG, C. (2003). Making History: A Guide for the Teaching and Learning of History in Australian 
Schools. Carlton South Vic: Curriculum Corporation.

TORRES BRAVO, P.A. (2001). Enseñanza del tiempo histórico. Historia, Kairós y Cronos. Una unidad didáctica para el aula de ESO. Madrid: Ediciones de la Torre.

VIÑAO FRAGO, A. (1994). Tiempo, historia y educación. Revista complutense de educación, $\mathrm{n}^{\circ}$ 2(5), 9-46. 
